\title{
Rectus femoris tendinopathy: a case report
}

\author{
Filiz Özdemir ${ }^{1} \odot$, Fatma Kızılay²$^{2}$, Şeyma Toy $^{2} \odot$, Zühal Altay $^{3} \odot$ \\ ${ }^{1}$ Department of Physical Therapy and Rehabilitation, Inönü University, Faculty of Health Sciences, Malatya, Turkey \\ ${ }^{2}$ Inönü University, Institute of Health Sciences, Malatya, Turkey \\ ${ }^{3}$ Department of Physical Therapy and Rehabilitation, Inönü University School of Medicine, Malatya, Turkey
}

DOI: $10.18621 /$ eurj.461932

\begin{abstract}
Tendinopathy may not be noticed in the differential diagnosis due to the complaint of pain spreading to the leg in the presence of nerve radiculopathy in the lumbar discopathy which is seen more frequently in the clinic shows similarity to the leg pain of musculus rectus femoris tendinopathy which is rarely seen. This situation leads to time, labor force and economic loss for both the patient and the health professionals. The case referred to the hospital with severe lower extremity pain and the complaint of incapability to walk. Despite the absence of findings in the imaging reports supporting a discopathy; conventional physiotherapy, intramuscular injection, and nerve blockage treatments were administered for the discopathy due to the clinical presentation. However, the complaints of the patient did not recover. The patient who had pain with a maneuver during exercise training was evaluated regarding tendinopathy and m.rectus femoris tendinitis was diagnosed with ultrasonography. The pain, quality of life and lower extremity functions of the patient were evaluated before and after treatment. The isolated deep transverse friction massage was applied on the tendon for the treatment. A positive change in pain, quality of life and lower extremity function scores was obtained after the five sessions of treatment.
\end{abstract}

Keywords: tendinopathy, rectus femoris, friction massage

Received: September 20, 2018; Accepted: March 20, 2019; Published Online: March 21, 2019

$\mathrm{T}$ endinopathy is a general term and is named differently according to the histological changes that occur in the tendon structure. Tendonitis, which is examined in the tendinopathy class, is a condition characterized by the inflammatory reaction in the tendon structure. Micro-tears occurred as a result of overpressing on the musculotendinous junctionusually cause to this process. The tendon is sensitive and painful to the stretching, pressing on and palpation [1]. Lower extremity pain and complaints of incapability to walk might be seen. Another cause of the lower extremity pain is lumbar discopathy (LD) [2]. Particularly in LD with radiculopathy, there is a complaint of pain spreading to the lower extremity [2]. Lower ex- tremity tendinopathies are conditions that can go unnoticed because of the pain that spreads to the leg, which can also be seen due to radiculopathy in LD; therefore may lead to time, labor force and financial loss for both the patient and the healthcare economics. Achieving success in treatment is possible with the correct treatment approach to the correct diagnosis. For this reason, it should be emphasized that the pain complaints related to LD and tendinopathy may be similar in patients with lower extremity pain and that this condition should be taken into consideration in the differential diagnoses. Treatment in tendinopathies consists of conservative phytotherapy agents, corticosteroidor non-steroid injections, and surgical treatment

Address for correspondence: Fatma Klzllay, Inönü University, Institute of Health Sciences, Malatya, Turkey E-mail:fatmakizilay@hotmail.com.tr 
options [1]. Deep transverse friction massage (DTFM) is a form of conservative treatment and should be considered as a cheap treatment technique that allows rapid and practical reduction of complaints that reduce the quality of life, such as pain and functional limitation [1]. In this case report, it was aimed to draw the attention to the fact that the patient who was followed by Physical Medicine and Rehabilitation (PMR), algology, neurosurgery and emergency outpatient clinics due to the severe pain in the lumbar and lower extremity areas was evaluated as LD because of the pain in the lumbar region and spreading to the leg, the treatment was planned for this diagnosis as the tendinopathy was ignored, and isolated DTFM without the combination of other physiotherapy agents in the treatment of tendinopathies was effective.

\section{CASE PRESENTATION}

A 42-year-old female patient referred to the PMR out patient clinic with severe left lower extremity pain and the complaint of incapability to walk which started acutely after heavy lifting at home. The patient had no chronic comorbidities. The patient was a housewife with sedentary lifestyle.

On the first examination of the patient regarding her complaint, there was the pain in the forward flexion of the back, and the straight leg lift test was positive. There was severe pain in the entire leg and around the left knee joint. The patient could not walk without any help. According to the Visual Analogue Scale (VAS), the lower extremity pain score was nine at rest. Table 1 summarizes the time line of the case,

Table 1. Summary of the patient's history and follow up with interventions given

\begin{tabular}{|c|c|}
\hline Date & Patient history and applications \\
\hline \multirow[t]{2}{*}{$\begin{array}{l}02^{\text {th }} \text { April } 2018- \\
11^{\text {th }} \text { May } 2018\end{array}$} & $\begin{array}{c}\text { A 42-year-old female patient was admitted to the PMR out patient clinic with } \\
\text { acute onset of severe left lower extremity pain and difficulty walking, } \\
\text { subsequent to heavy lifting at home. }\end{array}$ \\
\hline & $\begin{array}{c}\text { The patient had no accompanying chronic illness. Lumbosacral and knee MRI } \\
\text { was requested. } 30 \text { sessions of conventional physiotherapy and medical } \\
\text { treatment were applied. }\end{array}$ \\
\hline $\begin{array}{l}14^{\text {th }} \text { May } 2018- \\
17^{\text {th }} \text { May } 2018\end{array}$ & $\begin{array}{l}\text { The patient was admitted to the adult emergency, brain and neurosurgical } \\
\text { outpatient clinic with complaints of lumbar and lower extremity pain. } \\
\text { Intramuscular (IM) analgesic injection was made in the adult emergency } \\
\text { department and the patient was discharged with the recommendations. } \\
\text { Neurosurgery department suggested surgical treatment for discopathies due to } \\
\text { clinical complaints. }\end{array}$ \\
\hline $18^{\text {th }}$ May 2018 & $\begin{array}{l}\text { In the algology service, medial branch blockage was applied to the patient's L4- } \\
5 \text { and L5-S1 intervertebral spaces. The patient was called for control } 1 \text { week } \\
\text { later }\end{array}$ \\
\hline \multirow[t]{4}{*}{$25^{\text {th }}$ May 2018} & $\begin{array}{c}\text { On the day of the control the patient's pain was continuing. Exercise training } \\
\text { provided. }\end{array}$ \\
\hline & $\begin{array}{l}\text { The patient was counseled because of the pain while training the exercise by } \\
\text { the therapist.The PMR physician performed ultrasonography (USG) of the } \\
\text { patient's musculoskeletal system and was diagnosed with Rectus Femoris } \\
\text { Tendonitis. }\end{array}$ \\
\hline & $\begin{array}{c}\text { The treatment of he patient was planned and informed consent form was } \\
\text { signed. }\end{array}$ \\
\hline & $\begin{array}{l}\text { VAS, SF-36 and Lower Extremity Function Scales were applied before the } \\
\text { treatment. }\end{array}$ \\
\hline $\begin{array}{l}25^{\text {th }} \text { May } 2018- \\
01^{\text {th }} \text { June } 2018\end{array}$ & DTFM treatment was applied for 5 sessions every other day. \\
\hline $01^{\text {th }}$ July 2018 & $\begin{array}{l}\text { VAS, SF-36 and Lower Extremity Function Scale were applied at } 1 \text { month after } \\
\text { treatment }\end{array}$ \\
\hline
\end{tabular}


interventions given, and the progress of procedure conducted on the patient.

Magnetic resonance imaging (MRI) of the lumbosacral and knee regions was taken for the diagnostic evaluation of the patient. In the lumbosacral MRI, the vertebral corpus, intervertebral discs, and neural foramen were regular. As in the intervertebral discs, there were no abnormal findings besides the minimal hydration loss at L4-5 and L5-S1 levels. In the knee MRI report, there was a mild fluid increase around the knee joint, a minimal degeneration in the posterior horn of the medial meniscus, while the knee joint ligaments and lateral meniscus were normal. Thirty sessions of conventional physiotherapy including transcutaneous electrical nerve stimulation (TENS), ultrasound and superficial heating agents for the lumbar region, and TENS and cold agents for the knee region. The patient whose treatment was arranged with analgesic and anti-inflammatory medication at the end of the therapy was discharged. Within one week following the physiotherapy treatment, the patient was found out to refer to the outpatient clinics of the emergency department, neurosurgery, and algology on different days with the complaint of the lumbar and lower extremity pain. While the patient was discharged with the suggestions after intra muscular analgesic injection in the adult emergency department, the neurosurgery clinic offered surgical treatment for discopathy due to the patient's clinical complaints. The patient who did not accept the surgical treatment option, underwent medial branch blockage to the intervertebral spaces of L4-5 and L5$\mathrm{S} 1$ in the algology clinic. She was reported to have decreased back pain by $50 \%$ after the blockage treatment and was discharged with a control planned after one week. Due to the continuing lower extremity pain in the control examination, the patient was directed to the PMR outpatient clinic. Here the MRI of the patient's sacroiliac region was requested. The MRI of the patient which was evaluated according to The Assessment of Spondyloarthritis Society (ASAS) criteria [3] had no pathology. The patient was directed to a physiotherapist for exercise advice. Due to the occurrence of severe pain in the complete passive flexion of the patient's hip during the exercise training, the physiotherapist consulted with a physician. There was tenderness in the examinationby palpation on the tendon which was approximately $8 \mathrm{~cm}$ distal to the spina iliaca anterior superior (SIAS). The pain associated with the compression of the tender part in the complete passive flexion of the hips was indicative of the presence of tendinopathy [1]. The diagnosis was confirmed by USG of the musculoskeletal system made by a specialist physician. In the USG examination; there was hypoecotic edema in the synovial sheath and around the rectus femoris tendon; the tendon was thickened and there was mai adjacent to the tendon. These findings obtained by USG indicated tendinopathy. In the evaluation of soft tissues such as tendons USG is accepted as a reliable, noninvasive and economical method [4].

Before starting the study, patient was informed about the treatments and evaluations to be made by the physician and physiotherapist, and a written consent form was signed. Afterward, the treatment of the patient was planned and applied. Manual therapy techniques have an essential role in the treatment of tendinopathies [1]. Transverse friction application was made in the treatment; while the patient was in the semi-supine position, the physiotherapist located the tendon approximately $8 \mathrm{~cm}$ below the SIAS and placed the distal phalanges of the second and third fingers on the tendon. The first finger was placed on the trochanter major of the femur to applycounter pressure. DTMF was applied with the rhythmic flexion-extension movements of the wrist. DTFM was continued to be applied for 10 minutes after the sensation of numbness in the region was obtained. Figure 1 presents the technic of DTFM application. This application was repeated as five sessions as on

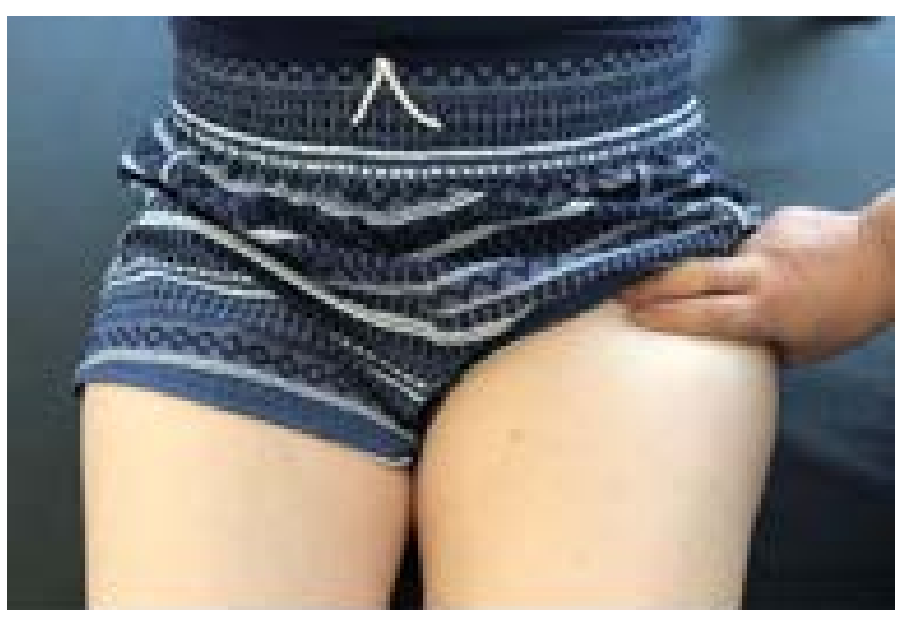

Figure 1. Application of DTFM on musculus rectus femoris tendon. 
every other day [1]. During this period, no additional medication was given to the patient.

The efficacy of the applied treatment was assessed regarding pain, quality of life, and lower extremity functions before the treatment (BT) and after the treatment (AT) at the first month. The pain was assessed with VAS, the quality of life with Short form36 (SF-36) [5], lower extremity functions with Lower Extremity Function Scale [6] According to VAS, the pain of the patient was 9 at rest BT, immediately AT 4 , and 0 after one month AT. The lower extremity function scale score was 10 BT and 71 at first month AT. According to the SF-36, physical functioning score of the patient was 0 BT and 90 at first month AT, physical role functioning score was $0 \mathrm{BT}$ and 100 at first month AT, emotional role functioning score was 0 BT and 100 at first month AT, energy-fatigue-vitality score was $5 \mathrm{BT}$ and 75 at first month AT, emotional well-being score was $16 \mathrm{BT}$ and 80 at first month AT, social functioning score was $12,5 \mathrm{BT}$ and 87,5 at first month AT, pain score was 0 BT and 90 at first month AT, and general health perception score was $5 \mathrm{BT}$ and 70 at first month AT. Considering the scores obtained, it is seen that there is a significant improvement in the patient's pain, quality of life and lower extremity function after the treatment.

\section{DISCUSSION}

Rectus femoris tendinopathy is an uncommon condition even for the athletes. It is even rarer in the sedentary individuals [7]. Symptoms start as a slow and progressive pain and discomfort on the anterior aspect of the hip and are typically exacerbated by exercise, especially during jumping and running [7]. Patient history and clinical evaluation involving direct palpation of the tendon and resistant muscle activation are necessary to make the appropriate diagnosis [7]. USG and MRI techniques provide useful and valuable diagnostic information for planning the therapeutic strategies. Conservative treatment includes oral and topical anti-inflammatory drugs and physical therapies with a wide range of modalities [7]. Due to the similar complaints, it is necessary to distinguish tendinopathy from the lumbar and neck problems. Pain caused by the problems in the lumbar or neck region mayspread to the extremities and may be confused with other symptoms such as the motor or sensory disorders [2]. Our case study aimed to draw attention to the possibility of tendinopathy diagnosis in patients with lower extremity pain due to our patient was evaluated as LD, had a treatment in this direction and eventually was diagnosed as tendinopathy. There are limited studies on the differential diagnosis of tendinopathy. Literature report that, rectus femoris tendinopathy was more frequently seen as calcific tendinitis [8]. In our case, acute onset tendinopathy was present. The literature also reports treatment options for rectus femoris tendinopathy as options for nonsteroidal antiinflammatory drugs, extracorporeal shock wave therapy (ESWT), local TENS and other electrotherapeutic modalities [8]. A review study indicated that steroid-non steroid injections frequently used in the treatment of sport injuries and tendinopathies but long-term use of these drugs should be limited by the reason for preparing new injuries [9]. DTFM application with no known reported side effects, was used as a treatment option in our case and the pain, quality of life and lower extremity function scores of the patient were significantly improved at the end of 5 sessions. DTFM holds a significant place in the conservative treatment of tendinopathies [1]. In a systematic review study of DTFM in the treatment of tendinopathies, it was reported that there was insufficient evidence for DTFM which was used alone without combining with other conventional treatment agents [10]. The researchers preferred to apply the DTFM combined with other modalities more frequently in the treatment of tendinopathy $[11,12]$. In fact, DTFM alone may be an excellent alternative treatment as a non-invasive method which is cheap and give results in a short-term.

\section{CONCLUSION}

It can be seen from the results that the evaluation of the patients with lower extremity pain in terms of tendinopathy should not be overlooked in the differential diagnosis and DTFM can be used as a treatment option alone in the treatment of tendinopathy. Yet it is clear that there is a need for more controlled studies involving more samples and isolated applications to demonstrate the efficacy of DTFM in tendinopathies. 


\section{Informed consent}

Written informed consent was obtained from the patient for publication of this case report and any accompanying images.

\section{Conflict of interest}

The authors declared that there are no potential conflicts of interest with respect to the research, authorship, and/or publication of this article.

\section{REFERENCES}

[1] Yüksel İ. Manual therapy in orthopedic problems, Ankara:Kalkan Publishing, 2017:38-57.

[2] Furlan A, Duso M. Rehabilitation medicine for elderly patients. Cham: Springer, 2018:237-47.

[3] Poddubnyy D, Van Tubergen A, Landewé R, Sieper J, Van der Heijde D. Development of an ASAS-endorsed recommendation for the early referral of patients with a suspicion of axial spondyloarthritis. Ann Rheum Dis 2015;74:1483-7.

[4] Husseini JS, Chang CY, Palmer WE. Imaging of tendons of the knee: much more than just the extensor mechanism. J Knee Surg 2018;31:141-54.

[5] Ware JE, Snow KK, Kosinski M, Gandek B. SF-36 health survey: Manual and interpretation guide 2017; The Health Institute, New England Medical Center: Boston, 1993.

[6] Mehta SP, Fulton A, Quach C, Thistle M, Toledo C, Evans NA Measurement properties of the lower extremity functional scale: a systematic review. J Orthop Sports Phys Ther 2016;46:200-16.

[7] Dragoni S, Bernetti A. Rectus femoris tendinopathy. In: The Lower Limb Tendinopathies. Cham: Springer, 2016:67-84.

[8] Yang JH, Oh KJ. Endoscopic treatment of calcific tendinitis of the rectus femoris in a patient with intractable pain. J Orthop Sci 2013;18:1046-9.

[9] Mehallo CJ, Drezner JA, Bytomski JR. Practical management: nonsteroidal antiinflammatory drug (NSAID) use in athletic injuries. Clin J Sport Med 2006;16:170-4.

[10] Joseph MF, Taft K, Moskwa M, Denegar CR. Deep friction massage to treat tendinopathy: a systematic review of a classic treatment in the face of a new paradigm of understanding. J Sport Rehabil 2012;21:343-53.

[11] Loew LM, Brosseau L, Tugwell P, Wells GA, Welch V, Shea $B$, et al. Deep transverse friction massage for treating lateral elbow or lateral knee tendinitis. The Cochrane database of systematic reviews. 2014;11:CD003528.

[12] Olaussen M, Holmedal Ø, Mdala I, Brage S, Lindbæk M. Corticosteroid or placebo injection combined with deep transverse friction massage, Mills manipulation, stretching and eccentric exercise for acute lateral epicondylitis: a randomised, controlled trial. BMC Musculoskelet Disord 2015;16: 122. 